\title{
A Hybrid Optimization Technique for Solving Economic Emission Load Dispatch Problem
}

\author{
Nurzanariah Roslan ${ }^{1}$, P. Sheik Abdul Khader ${ }^{2}$, Aisyah Nordin ${ }^{3}$, Sabarina Jaafar ${ }^{4}$ \\ ${ }^{1,3,4}$ Department of Electrical and Electronics Engineering, College of Engineering, Universiti Tenaga Nasional, \\ Selangor, Malaysia, ${ }^{1}$ nurzanariah@ @uniten.edu.my, ${ }^{3}$ aisyahnordin97@ gmail.com, ${ }^{4}$ sabarina@ uniten.edu.my \\ ${ }^{2}$ Department of Computer Science and Engineering, BSA Crescent Institute of Science \& Technology, Vandalur, \\ Chennai, Tamil Nadu, India, ${ }^{2}$ psakhader@ crescent.education
}

\begin{abstract}
This paper presents the application of a hybrid optimization technique termed as Immune-Evolutionary Programming (IEP) to solve Economic Emission Load Dispatch (EELD) of power system. IEP has been tested on the IEEE 30-Bus Reliability Test System (RTS) with two case studies: base case and loaded case. The objective of the optimization process is to minimize the total emission. Total system loss and total generation cost are calculated and observed while minimizing the emission. It is found that IEP is suitable to be used to solve EELD problemin giving better total emission, total system loss and total generation cost compared to the pre-optimization results for the both base case and loaded case.
\end{abstract}

Key words : Hybrid Optimization Technique, Economic Emission Load Dispatch, Artificial Immune System, Evolutionary Programming.

\section{INTRODUCTION}

Electricity generation in Malaysia is heavily dependent on generating units powered by fossil fuel in the production of electricity. Environmental pollution is caused by the release of acidic gasses, such as carbon monoxide $(\mathrm{CO})$, carbon dioxide $\left(\mathrm{CO}_{2}\right)$, sulfur dioxide $\left(\mathrm{SO}_{2}\right)$, and nitrogen oxides $\left(\mathrm{NO}_{\mathrm{x}}\right)$, which pollute and corrode the Earth's air. While numerous alternatives have been introduced and implemented in the country, such as the hydroelectric power plant and renewable energy technology, fossil fuel remains the main source of electricity generation.

EELD has therefore drawn the researchers' attention to a relatively good dispatch scheme due to the growing concern about the environmental pollution caused by thermal power plants. This would not only bring great economic benefit but also reduce the emission of pollutants. Major problems require engineers to find an optimal solution that simultaneously minimizes fuel use and emissions of hazardous gases. EELD deals with reducing fuel costs through considering optimum power generation in each generating unit of the power generation network, whereas pollution dispatch deals with minimizing the emission of harmful gases and particulate matter from the particular system. These targets are contradictory in nature and cannot be optimized simultaneously for single goal EELD.

Over the past decades, the EELD problem has been solved using a variety of optimization methods. A holistic review of EELD optimization strategies has been conducted in [1]. Such approaches can usually be divided into conventional methods, non-conventional methods and hybrid methods to solve the complex non-linear problem of non-liner constraints. For solving EELD, the traditional approaches based on mathematical programming methods such as Lagrange relaxation [2], lambda iteration method [3], linear programming [4], quadratic programming [5], Newton-Raphson [6] and gradient method [7] were initially applied. Classical methods have certain benefits, such as they have no problem-specific parameters to determine, their optimality is proved mathematically and some of them are computationally quick [1]. Nonetheless, these conventional methods cannot work satisfactorily in solving EELD problem as they are sensitive to initial estimates and converge into optimal local solution, sensitivity to the initial starting points, in addition to their computational complexity when the problem becomes complex, i.e. non-smooth, non-convex, non-monotonically increasing cost functions etc. [8,9].

A large number of heuristic techniques have been introduced over the past two decades and have attracted researchers' attention in solving EELD because of the ability to fulfill non-smooth cost function compared to conventional methods [10]. With the development of these evolutionary programming, the research focus has shifted to handling both emission pollution minimization targets and cost minimization at the same time without combining them into a single weighted target. The researchers became particularly evolutionary algorithms (EAs) to artificial intelligent techniques. Both meta-heuristics, respectively, use processes inspired by Darwinian Biological Evolution Theory and 
Social Interaction. These experiments have shown that EAs can effectively solve most of the inconveniences of conventional methods [11]- [14]. Some of the examples of these algorithms are evolutionary programming (EP) [15], particle swarm optimization (PSO) [13], differential evolution (DE) [16], chemical reaction optimization (CRO) [17] and summation based multi-objective differential evolution algorithm (SMODE) [18].

In this paper, the application of a hybrid optimization technique termed as Immune-Evolutionary Programming (IEP) for solving EELD problem is presented. The objective of this optimization problem is to minimize the total emission of three pollutants which are nitrogen oxides $\left(\mathrm{NO}_{\mathrm{x}}\right)$, sulfur oxides $\left(\mathrm{SO}_{\mathrm{x}}\right)$, and carbon dioxide $\left(\mathrm{CO}_{2}\right)$ that emitted by the fossil-fueled generating units. Total generation cost and total system loss are observed while optimizing the total emission.

\section{EELD PROBLEM FORMULATION}

The cost of managing emissions stems from the need for power utilities to reduce their pollutant rates below the annual emission allowances allotted for the coal units affected. Total emission can be decreased by reducing the three main pollutants that are: nitrogen oxides $\left(\mathrm{NO}_{\mathrm{x}}\right)$, sulfur oxides $\left(\mathrm{SO}_{\mathrm{x}}\right)$, and carbon dioxide $\left(\mathrm{CO}_{2}\right)$. In a linear equation, the objective function that minimizes total emissions can be represented as the sum of all three pollutants resulting from real power generators as follows.

$$
F_{E}=\sum_{i=1}^{n}\left(a_{i}+b_{i} P_{g i}+c_{i} P_{g i}^{2}+d_{i} \exp \left(e_{i} P_{g i}\right)\right)
$$

Where $a_{i}, b_{i}, c_{i}, d_{i}$ and $e_{i}$ are the characteristic coefficients of the generator emission.

While minimizing the total emission, total generation cost and total system are also calculated using equation (2) and equation (3), respectively.

$$
\begin{gathered}
C_{\text {total }}=\sum_{i=1}^{n} C_{i}\left(P_{i}\right), i \in\{1,2, \ldots, n\} \\
P_{\text {loss }}=\sum_{k=1}^{l} g_{k}\left[V_{i}^{2}+V_{j}^{2}-2 V_{i} V_{j} \cos \left(\delta_{i}-\delta_{j}\right), k\right. \\
\in\{1,2, \ldots, l\}
\end{gathered}
$$

Where:

$C_{i}\left(P_{i}\right)=$ the cost of production for $i t h$ generating unit,

$n=$ the number of the generating units in the

system,

$g_{k}=$ conductance of $k^{\text {th }}$ line,

$V_{i}$ and $\delta_{i}=$ voltage magnitude and angle of bus $i$, respectively,

$V_{j}$ and $\delta_{j}=$ voltage magnitude and angle of bus $j$, respectively, and

$l=$ number of lines in the system.
EELD problem is associated with the following constraints:

\subsection{OperatingLimits of Generating Units}

Every generating unit used has its own cost function that could be different from one another. It depends on the capacity of the generating units and the type of fuel used. The operating limits of a generating unit can be represented as follows:

$$
P_{i(\min )} \leq P_{i} \leq P_{i(\max )}, i \in\{1,2, \ldots, n\}
$$

Where $P_{i(\min )}$ and $P_{i(\max )}$ represents the minimum and maximum operating limit of $i t h$ generating unit, respectively.

\subsection{Power Balance Constraint}

It must be ensured that that the power generated meets the demand. Consequently, the net power generated must be equivalent to the total system loss and the demand required. This constraint can be represented by equation (5).

$$
P_{\text {generate }}=P_{\text {loss }}+P_{\text {demand }}
$$

\section{IMMUNE-EVOLUTIONARY PROGRAMMING FOR SOLVING EELD PROBLEM}

The flowchart of Immune-Evolutionary Programming to solve EELD problem is illustrated in Figure 1.

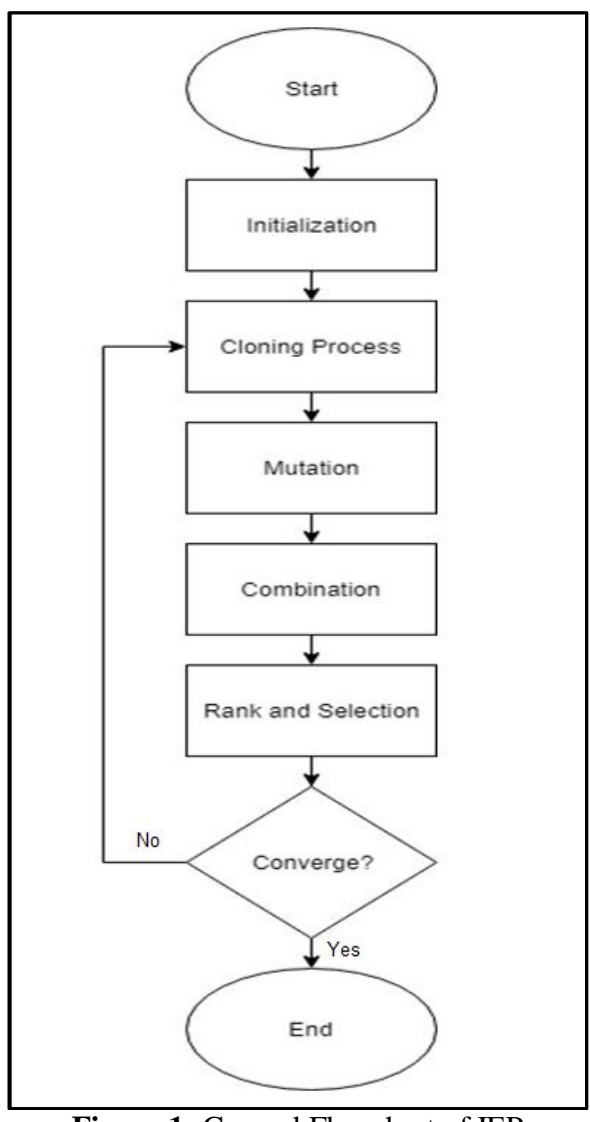

Figure 1: General Flowchart of IEP 
The process of solving the EELD problem using IEP can be explained in the following steps:

Step 1: Initialization

IEP begins with the process of initialization in which the values of the decision variables are determined. The variable deciding the outcome in EED problem is the real power produced by the generating units. In this stage the generators operating limit is taken into account. The best fitness value is measured from there and must be below the base value. Based on the literature, the ideal size of the initial population is twenty. Therefore, there will be twenty individuals of each decision variable at the end of this process.

Step 2: Cloning Process

The initial population then undergo the cycle of cloning, where they are multiplied by ten resulting in two hundred individuals. The name for this new population is called parents.

\section{Step 3: Mutation}

Subsequently, the parents are mutated using Gaussian mutation to produce their offspring. The offspring's population size is equivalent to the parents. The Gaussian mutation can be mathematically written as follows:

$$
x_{i+m, j}=x_{i+j}+N\left(0, \beta\left(x_{\text {jmax }}-x_{\text {jmin }}\right)\left(\frac{f_{i}}{f_{\text {max }}}\right)\right.
$$

Where:

$x_{i+m, j}=$ mutated cloned parent (offspring),

$x_{i+j} \quad=$ parent individual,

$\beta=$ mutation scale, $0<\beta<1$,

$x_{\text {jmax }}=$ maximum random number for every decision variable,

$x_{\text {jmin }}=$ minimum random number for every decision variable,

$f_{i} \quad=$ fitness for $i^{t h}$ random number, and

$f_{\max }=$ maximum fitness

Step 4: Combination

The next step is the process of combination where parents and offspring are combined to become a large population with a size of four hundred. These individuals will be ranked as the benchmark with their fitness in selection process.

Step 5: Selection

In this selection process, the combined individuals are ranked based on the best fitness values. Then the best twenty individuals are selected among them to undergo the convergence process.

\section{Step 6: Convergence Test}

A stopping criterion is set to indicate the optimal solution has been found by the algorithm. It is said to be converged when the difference between the first graded and the twentieth is
0.00001 as shown in equation (7).

$$
C_{\text {total }(20 t h)}-C_{\text {total(1st) }} \leq 0.00001
$$

\section{RESULTS AND DISCUSSION}

The IEEE 30-Bus Reliability Test System (RTS) has been used to demonstrate the implementation of IEP to solve EELD problem. There are six generating units in the system. Two case studies are introduced to solve the EELD problem of the IEEE 30-Bus RTS. The first case study is called as base case, which the original data of the system are used to solve EELD problem. Then the second case study is loaded condition. The real power demand for this second case is increased by $100 \%$ to study its effect to the EELD solution. Ten runs were performed for each case to study the performance of IEP in solving EELD problem. Prior to the IEP implementation, pre-optimization results of the IEEE 30-Bus RTS was recorded. This pre-optimization results are based on the load flow solution of the IEEE 30-Bus RTS. The results are shown in Table 1.

\begin{tabular}{|c|c|c|}
\hline $\begin{array}{l}\text { Total System Loss } \\
\text { (MW) }\end{array}$ & $\begin{array}{c}\text { Total } \\
\text { Generation Cost } \\
(\$ / \mathrm{hr})\end{array}$ & $\begin{array}{c}\text { Total } \\
\text { Emission } \\
\text { (ton/hr) }\end{array}$ \\
\hline 17.5985 & 850.2 & 0.8992 \\
\hline
\end{tabular}

Table 1: Pre-Optimization Results

\subsection{Case Study 1: Base Case}

As the total emission is set as the objective function of the optimization process, it can be observed from Table 2 that thetotal emission produced for every run is the same, unlike total generation cost and total system loss. From the table, the $3^{\text {rd }}$ run and the $9^{\text {th }}$ run produced the best EELD solution with total emission of 0.21 tons $/ \mathrm{hr}$, total generation cost of 606.1 $\$ / \mathrm{h}$ and total system loss of $7.05 \mathrm{MW}$. The real power output of the generating units are $60.02 \mathrm{MW}, 45.04 \mathrm{MW}, 39.03 \mathrm{MW}$, $24.72 \mathrm{MW}, 28.60 \mathrm{MW}$ and $26.92 \mathrm{MW}$ for $P_{g 1}, P_{g_{2}}, P_{g 3}, P_{g 4}$, $P_{g 5}$ and $P_{g 6}$, respectively.

Based on Figure 2, there are only three possible establishes of convergence value that IEP method managed to acquire. The lowest total emission obtained is 0.2114 tons $/ \mathrm{hr}$ at the $2^{\text {nd }}, 3^{\text {rd }}$ and $9^{\text {th }}$ runs. Though, it is not the most common converge value among the 10 runs. The value of total loss for this particular result is $7.057 \mathrm{MW}$ and the total generation cost is $606.1 \mathrm{\$} / \mathrm{hr}$. It appears that to achieve the lowest amount of emission, the cost is increasing in value as both parameters are non-linear to one another. Nonetheless, the values of the total generation cost and total emission are still lower than pre-optimization values which are $850.2 \$ / \mathrm{hr}$ and 0.8992 ton/hr, correspondingly. The value of real power output of generating units is also within the range of the constraints set in the program. 
The worst value of emission is the highest total emission produced by the system at the value of 0.2146 tons $/ \mathrm{hr}$. This value is very close with best result which is the lowest emission production obtained with the difference of 0.0032 tons/hr. At this amount of total emission issued, the amount of money needed to be used is $578.1 \$ / \mathrm{hr}$ with the difference of $28 \$ / \mathrm{hr}$ with the best result.

As referred to Figure 3, the worst total emission is 0.2146 tons $/ \mathrm{hr}$ while the best score of total emission is 0.2114 tons $/ \mathrm{hr}$. The median emission has proven that the IEP technique is able to reduce the EELD problem by lowering the original emission amount from 0.8992 tons/hr to an average of 0.2136 tons $/ \mathrm{hr}$. It is $76.25 \%$ reduction, which is a huge achievement.

\subsection{Case Study 2: Loaded Case}

Table 2: EELD Solution of the IEEE 30-Bus RTS for 10 Runs (Case Study 1)

\begin{tabular}{cccccccccc}
\hline \multirow{2}{*}{$\begin{array}{c}\text { No. } \\
\text { of } \\
\text { runs }\end{array}$} & \multicolumn{2}{c}{ Real Power Output of Generating Unit, $P_{g i}(\mathrm{MW})$} & $\begin{array}{c}\text { Total } \\
\text { System }\end{array}$ & $\begin{array}{c}\text { Total } \\
\text { Generation }\end{array}$ & $\begin{array}{c}\text { Total } \\
\text { Emission } \\
\text { (tons/hr) }\end{array}$ \\
\hline 1 & & $P_{g 2}$ & $P_{g 3}$ & $P_{g 4}$ & $P_{g 5}$ & $P_{g 6}$ & $\begin{array}{c}\text { Loss } \\
(\mathrm{MW})\end{array}$ & \\
\hline Cost $(\$ / \mathrm{h})$ & & \\
\hline 2 & 60.02 & 45.04 & 39.03 & 24.72 & 28.60 & 26.92 & 7.05 & 606.1 & 0.21 \\
\hline 3 & 60.02 & 45.04 & 39.03 & 24.72 & 28.60 & 26.92 & 7.05 & 606.1 & 0.21 \\
\hline 4 & 65.24 & 33.16 & 37.21 & 27.40 & 25.89 & 23.92 & 7.83 & 578.1 & 0.21 \\
\hline 5 & 65.24 & 33.16 & 37.21 & 27.40 & 25.89 & 23.92 & 7.83 & 578.1 & 0.21 \\
\hline 6 & 65.24 & 33.16 & 37.21 & 27.40 & 25.89 & 23.92 & 7.83 & 578.1 & 0.21 \\
\hline 7 & 65.24 & 33.16 & 37.21 & 27.40 & 25.89 & 23.92 & 7.83 & 578.1 & 0.21 \\
\hline 8 & 65.24 & 33.16 & 37.21 & 27.40 & 25.89 & 23.92 & 7.83 & 578.1 & 0.21 \\
\hline 9 & 60.02 & 45.04 & 39.03 & 24.72 & 28.60 & 26.92 & 7.05 & 606.1 & 0.21 \\
\hline 10 & 65.24 & 33.16 & 37.21 & 27.40 & 25.89 & 23.92 & 7.83 & 578.1 & 0.21 \\
\hline
\end{tabular}

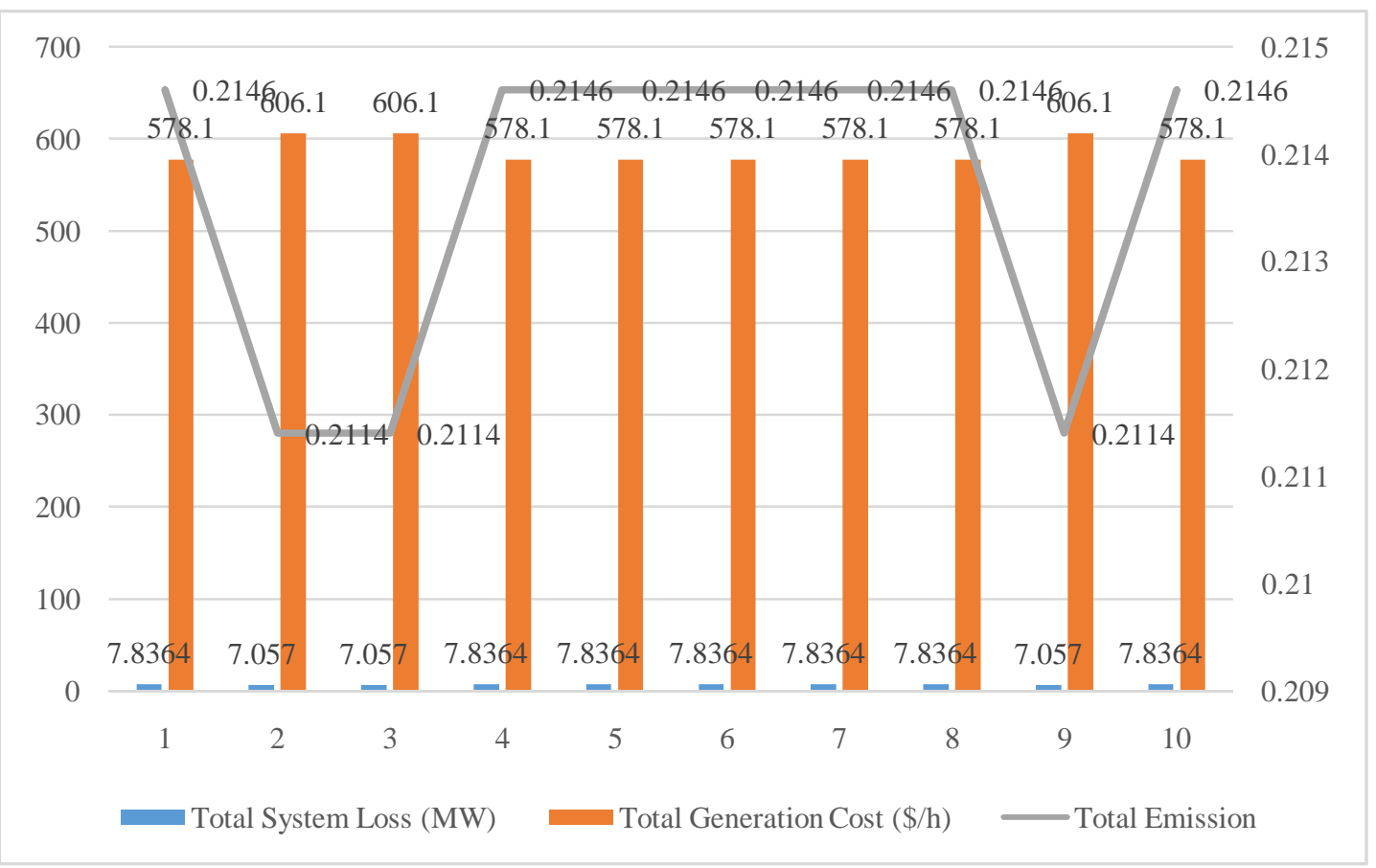

Figure 2: Total Emission vs Number of Run (Case Study 1) 


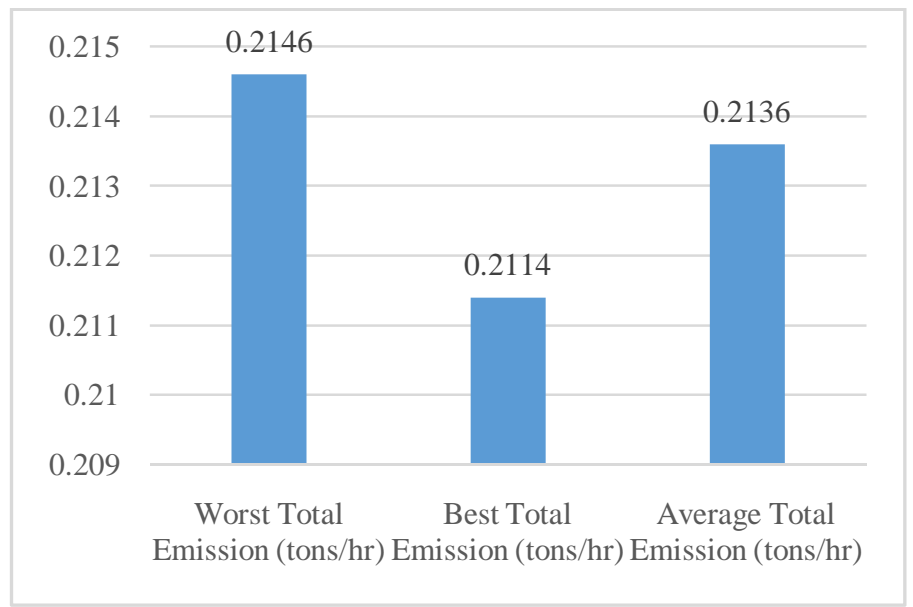

Figure 3: Comparison of Total Emission (Case Study 1)

Table 3: EELD Solution of the IEEE 30-Bus RTS for 10 Runs (Case Study 2)

\begin{tabular}{|c|c|c|c|c|c|c|c|c|c|}
\hline \multirow{2}{*}{$\begin{array}{l}\text { No. } \\
\text { of } \\
\text { runs }\end{array}$} & \multicolumn{6}{|c|}{ Real Power Output of Generating Unit, $P_{g i}(\mathrm{MW})$} & \multirow{2}{*}{$\begin{array}{c}\text { Total } \\
\text { System } \\
\text { Loss } \\
(\mathrm{MW})\end{array}$} & \multirow{2}{*}{$\begin{array}{c}\text { Total } \\
\text { Generation } \\
\text { Cost }(\$ / \mathrm{h})\end{array}$} & \multirow{2}{*}{$\begin{array}{c}\text { Total } \\
\text { Emission } \\
\text { (tons } / \mathrm{hr} \text { ) }\end{array}$} \\
\hline & $P_{g 1}$ & $P_{g 2}$ & $P_{g 3}$ & $P_{g 4}$ & $P_{g 5}$ & $P_{g 6}$ & & & \\
\hline 1 & 65.24 & 33.16 & 37.21 & 27.40 & 25.89 & 23.92 & 7.83 & 578.1 & 0.21 \\
\hline 2 & 60.02 & 45.04 & 39.03 & 24.72 & 28.60 & 26.92 & 7.05 & 606.1 & 0.21 \\
\hline 3 & 60.02 & 45.04 & 39.03 & 24.72 & 28.60 & 26.92 & 7.05 & 606.1 & 0.21 \\
\hline 4 & 65.24 & 33.16 & 37.21 & 27.40 & 25.89 & 23.92 & 7.83 & 578.1 & 0.21 \\
\hline 5 & 65.24 & 33.16 & 37.21 & 27.40 & 25.89 & 23.92 & 7.83 & 578.1 & 0.21 \\
\hline 6 & 65.24 & 33.16 & 37.21 & 27.40 & 25.89 & 23.92 & 7.83 & $\begin{array}{l}578.1 \\
\end{array}$ & 0.21 \\
\hline 7 & 65.24 & 33.16 & 37.21 & 27.40 & 25.89 & 23.92 & 7.83 & 578.1 & 0.21 \\
\hline 8 & 60.02 & 45.04 & 39.03 & 24.72 & 28.60 & 26.92 & 7.05 & 606.1 & 0.21 \\
\hline 9 & 65.24 & 33.16 & 37.21 & 27.40 & 25.89 & 23.92 & 7.83 & 578.1 & 0.21 \\
\hline 10 & 52.24 & 36.45 & 37.50 & 23.65 & 28.35 & 15.33 & 8.31 & 521.5 & 0.21 \\
\hline
\end{tabular}

The real power load of the IEEE 30-Bus RTS is increased by $100 \%$. After that, IEP is employed to solve EELD problem of the system, again for 10 runs to minimize total emission. The results obtained are tabled in Table 3.

Figure 4 shows the values of total system loss, total generation cost and total emission for 10 runs with the objective function of minimizing the total emission. The lowest value of total power emission is 0.2114 tons $/ \mathrm{hr}$ at the $2^{\text {nd }}, 3^{\text {rd }}$ and $8^{\text {th }}$ runs, which only covers $30 \%$ of overall 10 test runs. The values of total system loss and total generation cost at this set of solution are 7.0570 MW and $606.1 \$ / \mathrm{hr}$, respectively. Remarkably, the pattern is precisely identical with the base case. This is proof that the IEP can still solve EELD problem flawlessly even when the real power load of IEEE 30-Bus RTS isdoubled. The values of each real power output of the generating units are also within range of restrictions set in the
program.The value of total emission is the highest at the $1^{\text {st }}$, $4^{\text {th }}, 5^{\text {th }}, 6^{\text {th }}, 7^{\text {th }}$ and $9^{\text {th }}$ runs with the value of 0.2146 tons $/ \mathrm{hr}$. Still, the total system loss is lower at $7.8364 \mathrm{MW}$ compared to $7.0570 \mathrm{MW}$ obtained at $0.2114 \mathrm{tons} / \mathrm{hr}$. While the total generation cost obtained is $578.1 \$ / \mathrm{hr}$. It can be seen that the cost value compensates the higher emission compared to the lower emission value. At the very last run, the value of total emission is 0.2116 tons $/ \mathrm{hr}$ with $8.3135 \mathrm{MW}$ of total generation loss. While the total generation cost is $521.5 \$ / \mathrm{hr}$. For this run, the total system loss is the highest, however the total generation cost is the lowest and the total emission is near to the lowest emission.

Based on Figure 5, the worst value of total emission is 0.2146 tons $/ \mathrm{hr}$, while the best total emission is 0.2114 tons $/ \mathrm{hr}$. Evidently, both the best and worst valuesof total emission are similar to the base case even when the real power load 


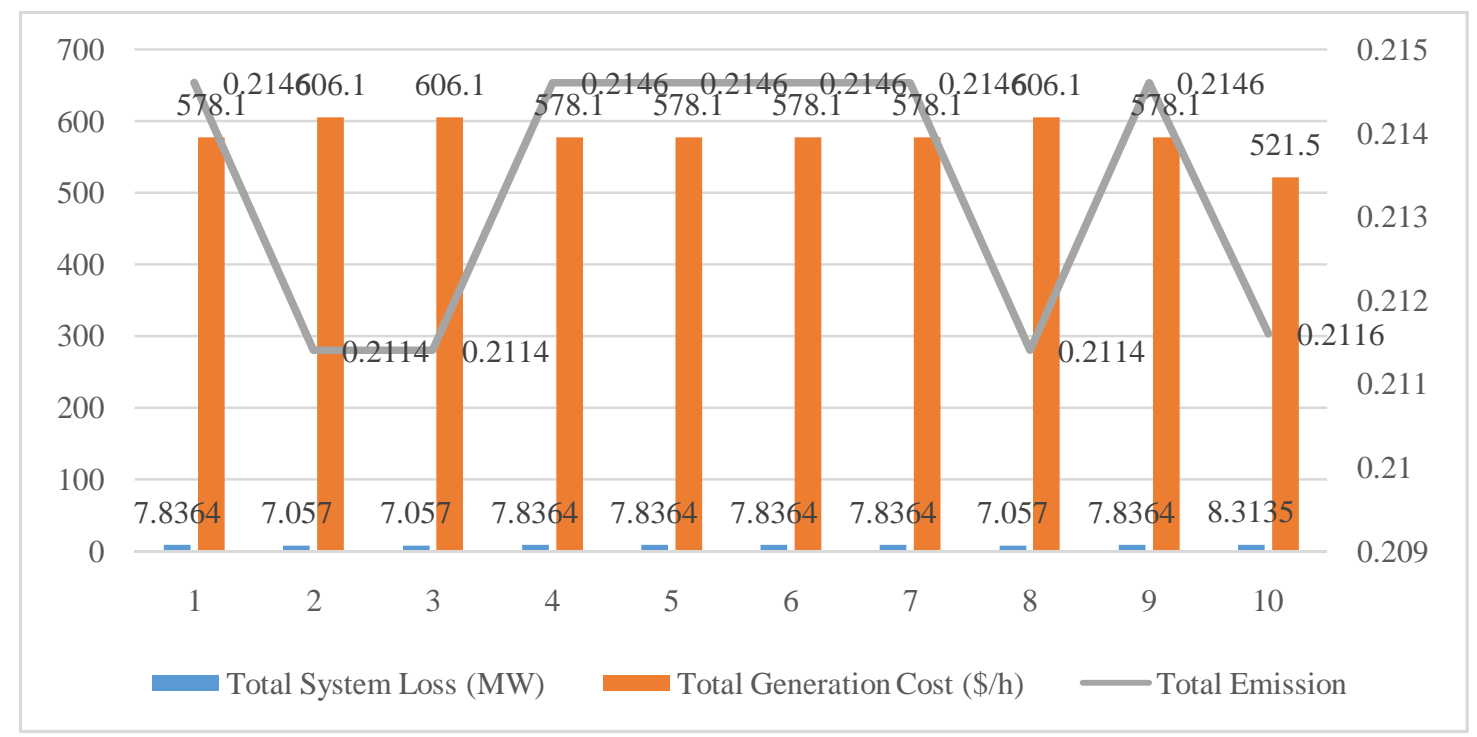

Figure 4: Total Emission vs Number of Run (Case Study 2)

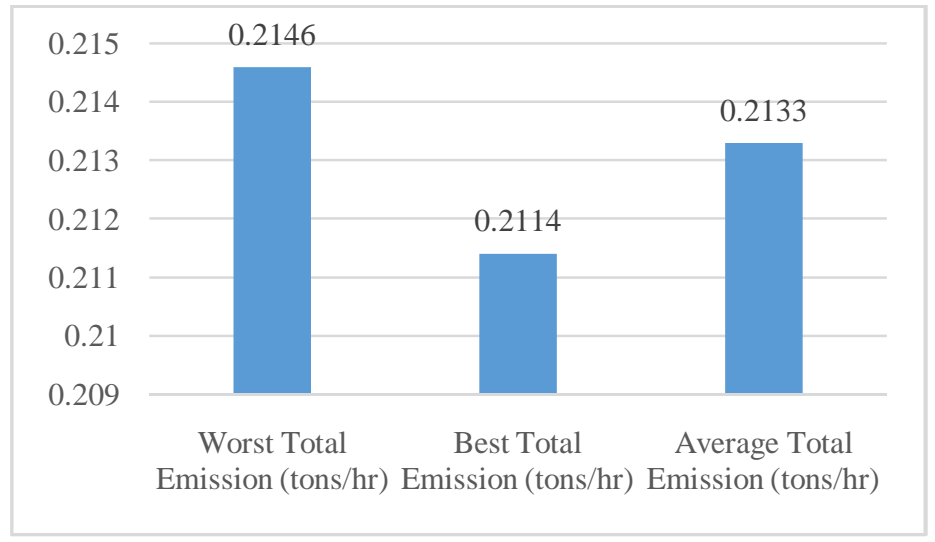

Figure 5: Comparison of Total Emission (Case Study 2)

isincreased by $100 \%$. The average total emission for this loaded case is 0.2133 tons $/ \mathrm{hr}$. The aggregate value of this loaded case is still significantly lower than the pre-optimization value of total emission without modification in the IEEE 30-Bus RTS.

\section{CONCLUSION}

This paper has presented the application of a hybrid optimization technique termed as Immune-Evolutionary Programming (IEP) to solve EELD for total emission minimization. Based on the EELD solution of the IEEE 30-Bus RTS produced by IEP for the two case studies (base case and loaded case), it can be concluded that IEP is a powerful optimization technique to be used to solve EELD problem for total emission minimization.

For future development, the EELD can be solved using IEP with multiple objectives optimization instead of only single objective optimization in this paper to give better EELD solution.

\section{ACKNOWLEDGEMENT}

The authors would like to acknowledge the Universiti Tenaga Nasional (UNITEN) for the financial support of this project. This research is supported by UNITEN under the BOLD Research Grant 2020 with project code: UNITEN/RMC(BOLD)/1/14/AL/2020/58.

\section{REFERENCES}

\section{(Periodical style)}

1. F. P. Mahdi, P. Vasant, V. Kallimani, J. Watada, P. Y. S. Fai, and M. Abdullah-Al-Wadud. A holistic review on optimization strategies for combined economic emission dispatch problem, Renew. Sustain. Energy Rev., vol. 81, no. March 2017, pp. 3006-3020, 2018.

2. Yimu Fu ; Mingbo Liu and Licheng Li, Multiobjective Stochastic Economic Dispatch With Variable Wind Generation Using Scenario-Based Decomposition and Asynchronous Block Iteration,IEEE Transactions on Sustainable Energy, vol. 7, no. 1, pp. 139-149, 2017. 
3. P. Aravindhababu and K. R. Nayar, Economic dispatch based on optimal lambda using radial basis function network,Int. J. Electr. Power Energy Syst., vol. 24, no. 7, pp. 551-556, 2002.

4. J. Parikh and D. Chattopadhyay, A multi-area linear programming approach for analysis of economic operation of the Indian power system, IEEE Transactions on Power Systems, vol. 11, no. 1, pp. 52-58, 1996.

5. Ghulam Abbas, Jason Gu, Umar Farooq, Muhammad Usman Asad and Mohamed El-Hawary, Solution of an Economic Dispatch Problem Through Particle Swarm Optimization: A Detailed Survey - Part I, IEEE Access, vol. 13, no. 2, pp. 320-325, 1998.

6. Rizk M. Rizk-Allah, Ragab A. El-Sehiemy and Gai-Ge Wang,A novel parallel hurricane optimization algorithm for secure emission/economic load dispatch solution, Applied Soft Computing, vol. 63, pp. 206-222, 2018.

7. M. H. Mansor, I. Musirin and M. M. Othman, Immune Log-Normal Evolutionary Programming (ILNEP) for solving economic dispatch problem with prohibited operating zones, in 2017 4th International Conference on Industrial Engineering and Applications (ICIEA), Nagoya, 2017, pp. 163-167.

8. B. Y. Qu, Y. S. Zhu, Y. C. Jiao, M. Y. Wu, P. N. Suganthan, and J. J. Liang, "A survey on multi-objective evolutionary algorithms for the solution of the environmental/economic dispatch problems, Swarm Evol. Comput., vol. 38, no. July 2016, pp. 1-11, 2018.

9. A. Y. Abdelaziz, E. S. Ali, and S. M. Abd Elazim, Combined economic and emission dispatch solution using Flower Pollination Algorithm,Int. J. Electr. Power Energy Syst., vol. 80, pp. 264-274, 2016.

10. N. I. Nwulu and X. Xia, Multi-objective dynamic economic emission dispatch of electric power generation integrated with game theory based demand response programs, Energy Convers. Manag., vol. 89, pp. 963-974, 2015.

11. M. Basu, A simulated annealing-based goal-attainment method for economic emission load dispatch of fixed head hydrothermal power systems,Int. J. Electr. Power Energy Syst., vol. 27, no. 2, pp. 147-153, 2005.

12. M. Modiri-Delshad and N. A. Rahim, Multi-objective backtracking search algorithm for economic emission dispatch problem,Appl. Soft Comput. J., vol. 40, pp. 479-494, 2016.

13. K. Mason, J. Duggan, and E. Howley, Multi-objective dynamic economic emission dispatch using particle swarm optimization variants,Neurocomputing, vol. 270, pp. 188-197, 2017.

14. M. H. Mansor, M. R. Irving, and G. A. Taylor, A decomposition/aggregation method for solving electrical power dispatch problems, in 2012 47th International Universities Power Engineering Conference (UPEC), 2012, pp. 1-7.

15. T. Jayabarathi, K. Jayaprakash, D. N. Jeyakumar, and T. Raghunathan, Evolutionary programming techniques for different kinds of economic dispatch problems,Electr. Power Syst. Res., vol. 73, no. 2, pp. 169-176, 2005.

16. R. Balamurugan and S. Subramanian, Emission-constrained dynamic economic dispatch using opposition-based self-adaptive differential evolution algorithm, Int. Energy J., vol. 10, no. 4, pp. 267-276, 2009.

17. M. Mazadi, W. Rosehart, and H. Zareipour, Impact of Wind Generation on Electricity Markets: A Chance-Constrained Nash Cournot model,Iran. J. Sci. Technol. - Trans. Electr. Eng., vol. 36, no. E1, pp. 51-66, 2012.

18. B. Y. Qu, J. J. Liang, Y. S. Zhu, Z. Y. Wang, and P. N. Suganthan, Economic emission dispatch problems with stochastic wind power using summation based multi-objective evolutionary algorithm," Inf. Sci. (Ny)., vol. 351, pp. 48-66, 2016. 